УДК 33

DOI $10.21661 / \mathrm{r}-474951$

\title{
О.В. Сушенцева
}

\section{ЭКОНОМИЧЕСКИЕ ФАКТОРЫ}

Аннотация: нефтедобыча давно является основным источником пополнения бюджета страны и отправной точкой для развития других отраслей промышленности, поэтому эффективность функиионирования нефтяного комплекса РФ и его привлекательность для инвестищий является ключевым вопросом для государства. В данной статье автор акиентирует внимание на факторах, которые так или иначе формируют общую картину развития, и на этой основе строит эконометрическую модель.

Ключевые слова: нефть, нефтедобыча, нефтяной комплекс, факторы, инфраструктура, промышленность, Россия, экономика.

\section{O.V. Sushentseva}

\section{ECONOMIC FACTORS}

Abstract: oil production has long been considered the major source of replenishment of the budget of the country and the starting point for the development of other industries so today the efficiency of the oil complex functioning of the Russian Federation and its investment attractiveness is a key problem for the state. In this article the author focuses attention on factors that one way or another form picture of development and on this foundation obtains data for the econometric model.

Keywords: oil, oil production, oil complex, factors, infrastructure, industry, Russia, economy.

Актуальность темы исследования заключается в том, что на сегодняшний день нефтяной комплекс является сложнейшей и, несомненно, важной развивающейся системой, на деятельность которой оказывает влияние большое количество факторов. Исходя из этого, рассмотрение данных факторов позволяет 
определить эффективность нефтяного комплекса РФ и выявить какие из них имеют принципиальную важность для всей отрасли нефтедобычи.

Цель исследования заключается в том, чтобы представить общую картину развития нефтяной отрасли в России, определить вышеупомянутые факторы и степень их влияния и, наконец, математически представить полученные результаты с помощью построения эконометрической модели.

Таким образом, предметом исследования является факторы, которые непосредственно формируют отрасль нефтедобычи в России.

В ходе исследования были использованы такие методы как теоретический анализ источников по данной теме, сравнение и метод линейного тренда.

В первую очередь необходимо рассмотреть внешние факторы, оказывающие влияние на функционирование нефтяного комплекса, самые значимые из которых - экономические и политические.

Экономические факторы включают в себя «торговые войны», международное разделение труда, доминирующее положение на мировом рынке какого-либо государства и мировую экономическую ситуацию в целом.

К не менее важным внешним политическим относятся членство страны в каком-либо союзе или организации, установление или разрыв дипломатических отношений, объявление эмбарго на поставку товаров и услуг, внешняя политика государств по отношению к данной стране, предоставление режима наибольшего благоприятствования, участие страны в военно-политических союзах и так далее.

Внутренние факторы функционирования национальной экономики также отличаются разнообразием [3, с. 126].

1. Экономико-географические факторы включают в себя:

а) экономико-географическое положение страны.

В частности выделяются следующие географические особенности, характерные для России: обширная площадь, неравномерное заселение и хозяйственное освоение, богатство и многообразие природных условий и природных ресурсов; 
б) физико-географические условия (рельеф, климат и т. п.).

Природная уникальность состоит в том, что Россия - самое северное государство мира;

в) природные ресурсы, а именно те объекты и силы природы, которые на сегодняшнем уровне развития производительных сил могут использоваться для удовлетворения потребностей человека. К настоящему времени изучено не менее $80 \%$ территории страны.

2. Собственно экономические факторы [3, с. 134]:

а) структура экономики страны (отраслевая, социальная, территориальная и т. д.).

Социальная структура разделяет национальную экономику на определенные взаимосвязанные сектора. Отраслевая структура определяет отрасли экономики и характер, сущность взаимосвязи между ними. Территориальная структура подразумевает под собой анализ географического распределения производительных сил, в частности, деление национальной экономики на различные экономические районы. Для нынешней структуры промышленности России характерно наличие не только отраслевых, но и межотраслевых комплексов. Современная отраслевая структура национальной экономики России отличается доминированием топливно-энергетического комплекса (ТЭК), в который входит нефтяной сектор;

б) соотношение различных видов и форм собственности (федеральной, региональной, муниципальной, частной, собственности общественных организаций и т. д.).

Структура собственности играет немаловажную роль для нефтяного комплекса, по той причине, что именно она определяет характер и сущность происходящих в нем процессов, в частности производства, потребления, распределения. Для России характерно преобладание теневых отношений собственности, т.е. данные отношения протекают вне правового поля и в основном не регулируются государством;

в) состояние инфраструктуры (производственная, социальная, рыночная). 
В данном случае под инфраструктурой следует понимать совокупность единиц, функционирование которых в целом заключается в обеспечении нормального развития экономики страны, включая и нефтяной комплекс;

г) наличие международных транспортных коридоров.

Для обеспечения растущих объемов внешнеторговой деятельности, укрепления роли России в мировой хозяйственной системе необходимо создать и планомерно развивать российские международные транспортные коридоры, как существенные элементы формируемой международной евроазиатской транспортной инфраструктуры.

Основная часть грузопотоков внешнеторговых и транзитных перевозок приходится на оси Запад-Восток и Север-Юг и совпадает с главными направлениями перевозок в межрегиональном сообщении внутри страны, в районе которых сосредоточено более $80 \%$ населения и промышленного потенциала государства. Таким образом, развитие международных транспортных коридоров поспособствует удовлетворению не только внешним, но и внутренним экономическим интересам России;

д) консолидированный бюджет страны.

Именно консолидированный бюджет страны формирует представление о состоянии доходной и расходной частей бюджета, в соответствии с которым происходит перераспределение части стоимости ВВП. Направленность нефтяного комплекса на международный рынок делает Россию зависимой от мирового изменения цен. Вследствие чего более половины ВВП страны зависит от продажи ресурсов;

е) внешнеэкономические связи государства (внешняя торговля, миграция рабочей силы, импорт и экспорт капиталов и услуг).

Повышение уровня качества управления внешней экономикой в условиях кризиса российской экономики, безусловно, способствует оздоровлению промышленности, становится ведущим аспектом экономического роста и оказывает положительное воздействие на работу нефтяного комплекса;

ж) баланс производства и рынков сбыта. 
Установление баланса для успешного функционирования нефтяного комплекса требует постоянной корректировки показателей производства и сбыта относительно изменений спроса на рынке;

3) инвестиционная деятельность.

На сегодняшний день наблюдается повышенный интерес к российской нефти со стороны государств, которые ранее не являлись покупателями нефти, добытой на территории России. Однако данная тенденция создала новые внешние проблемы - так сейчас разрабатываются сразу два проекта нефтепровода в Восточной Сибири Ангарск - Дацин и Ангарск - Находка. Первый поддерживается Китаем, второй - Японией. Обе страны проявляют заинтересованность в строительстве данных нефтепроводов и в поступлении нефти из Восточной Сибири. В сложившейся ситуации перед Россией стоит сложный выбор. С одной стороны, КНР являлась и является значительным торговым и стратегическим партнером. Кроме того, предлагаемый вариант трубопровода дешевле. С другой стороны, вместе со строительством нефтепровода до Находки и экспортом нефти в Японию Россию ожидает широкое привлечение японских инвестиций и последующая возможность выхода на другие рынки экспорта.

3. Социально-демографические факторы характеризуют население страны, как один из основных элементов ее экономического потенциала, включая, например, такие факторы как занятость населения и демографическая ситуация [2, c. 158].

4. Инфраструктурные факторы оказывают прямое влияние на функционирование национальной экономики. В данном случае под инфраструктурой подразумевается комплекс производственных и непроизводственных отраслей, которые обеспечивают условия воспроизводства: транспорт, материально-техническое снабжение, наука, образование, здравоохранение, водоснабжение, охрана окружающей среды связь, торговля. В более широком смысле инфраструктура это составные части устройства политической и экономической жизни, которые обладают вспомогательным характером и обеспечивают деятельность экономической или политической системы в целом [2, с. 235]. 
К числу основных инфраструктурных факторов, сдерживающими развитие комплекса, относятся:

- высокая (более 50\%) степень износа основных фондов;

- ввод в эксплуатацию новых производственных мощностей сократился за от 2 до 6 раз;

- несоответствие производственного потенциала комплекса мировому научно-техническому уровню;

- отставание развития и объективный рост затрат на освоение перспективной сырьевой базы добычи углеводородов;

- отсутствие рыночной инфраструктуры и развитого энергетического рынка;

- высокая нагрузка на окружающую среду;

- практика продления ресурса оборудования закладывает будущее отставание в эффективности производства.

5. Организационно-управленческие факторы играют немаловажную роль, так как непосредственно воздействуют на организационную структуру экономики государства через такие составляющие как, например, структура органов управления экономикой, цели и методы управления, механизм управления, организация стратегического планирования и прогнозирования развития национальной экономики, разработка целевых программ в сфере экономики, формирование внешнеэкономической стратегии страны и так далее. Таким образом, именно от квалифицированного и основательно продуманного руководства деятельностью предприятий зависит выгодное функционирование национальной экономики, в частности и нефтяного комплекса [2, с. 257].

6. К правовым факторам можно отнести стабильность правовых норм, качество и проработанность нормативно-правовой базы, немаловажным является фактор коррумпированности экономики. Отсутствие развитого и стабильного законодательства, учитывающего в полной мере специфику функционирования предприятий нефтяного комплекса, является отрицательной особенностью России [2, с. 286]. 
Нефтяная индустрия была и остается существенным инструментом в решении внешнеполитических задач. Учитывая, что изменились возможности России оказывать влияние на внешних партнеров, потребовалось также создать новый действенный инструмент влияния, который бы отвечал новым рыночным и постоянно меняющимся геополитическим условиям. Таким инструментом являются мощные интегрированные компании такие как «Лукойл» и «Газпром».

Анализируя состояние российской дипломатии на сегодняшний день, можно сказать о первых шагах по использованию нефтяных возможностей России во внешней политике и о значении энергетической дипломатии в упрочении сотрудничества со странами СНГ. По сравнению с газом (стоимость газа зависит от цен на жидкое углеводородное топливо), нефть является существенным фактором развития отношений с Украиной и Белоруссией, нефтяная зависимость которых делает проводимую в странах политику более предсказуемой по отношению к нашей стране, и позволяет России более эффективно оказывать на них влияние.

На переговорах США и России, помимо подписания документов, всё чаще стала наблюдаться тенденция обсуждения роли нефтяного фактора. Регулярно обсуждается важность энергетического сотрудничества на переговорах и с представителями ЕС. Россия обеспечивает $32 \%$ потребления нефти в Европе, поэтому постоянный диалог с нашей страной по данному вопросу для ЕС крайне важен.

На азиатском направлении спрос на российскую нефть остается выше возможностей российских компаний по обеспечению данного рынка топливом. Поставки российского углеводородного сырья могут принести как положительный эффект (расширение производства, диверсификация рынков сбыта продукции, рост капиталовложений со стороны иностранных партнёров), так и дать начало созданию множества проблем.

Помимо этого, еще одним немаловажным аспектом российской внешней политики, неразрывно связанным с нефтью, остается сотрудничество РФ с нефтедобывающими странами, в особенности со странами ОПЕК. В течение долгого промежутка времени эти отношения находились в замороженном состоянии. 
При всем при этом Россия доказала способность приходить к консенсусу даже в кризисных ситуациях с ОПЕК.

Успешное функционирование нефтяного комплекса РФ заключается в получении общественного блага (результата) от использования нефти и продуктов её переработки. Эффективность, означает в исходном виде «действие», в экономической науке больше соотносится с «явлением», представляющим собой окончание определенного экономического процесса - части общего действия (впрочем, не всегда приводящего к позитивным результатам). Таким образом, вне зависимости от того, какой характер имеет данное действие, его эффективность можно измерить.

Эффективность функционирования нефтяного комплекса есть функционал от следующих переменных:

- степень удовлетворения различных потребностей отраслей комплекса;

- степень удовлетворения потребностей внешней среды (рынка) в продукции комплекса,

- степень удовлетворения потребностей регионов (выраженных в стратегии их развития) в функционировании комплекса;

- степень удовлетворения потребностей государства регионов (выраженных в стратегии развития страны) в функционировании комплекса.

Математически эффективность функционирования нефтяного комплекса можно описывать следующим образом:

$$
\mathrm{E}=\mathrm{F}(\mathrm{P} 1, \mathrm{P} 2, \mathrm{R}, \mathrm{S}, \mathrm{L}),
$$

где Е - эффективность; F - функционал; P1, P2 - степени удовлетворения внутренних потребностей отраслей НК и потребностей внешней среды (рынка) соответственно; R - степень удовлетворения потребностей регионов; $\mathrm{S}$ - степень удовлетворения потребностей государства; L - степень удовлетворения потребностей населения» [1].

«Показателями внешней эффективности функционирования НК являются: для отраслей-потребителей продукции НК соотношение темпов роста цен на производимую продукцию и темпов роста цен на продукцию НК, для 
населения - темпы роста денежных доходов населения и темпов роста цен на продукцию НК. В общем виде внешняя эффективность функционирования НК для потребителей продукции может быть описана следующей формулой:

$$
\mathrm{Ev}=(\mathrm{Tp} / \mathrm{Tnk}-1)
$$

где Ev - внешняя эффективность функционирования НК для потребителей продукции НК; Тр - темпы роста цен на продукцию отрасли - потребителя продукции НК или темпы роста денежных доходов населения; Tnk - темпы роста цен на продукцию НК. Абсолютное значение показателя внешней эффективности характеризует ее количественное изменение, а положительное или отрицательное значение - качественное изменение (рост или падение)» [1]. Исходя из уравнения 2, можно сделать вывод: зависимость - нелинейная, следовательно, график модели будет выглядеть следующим образом (гипербола):

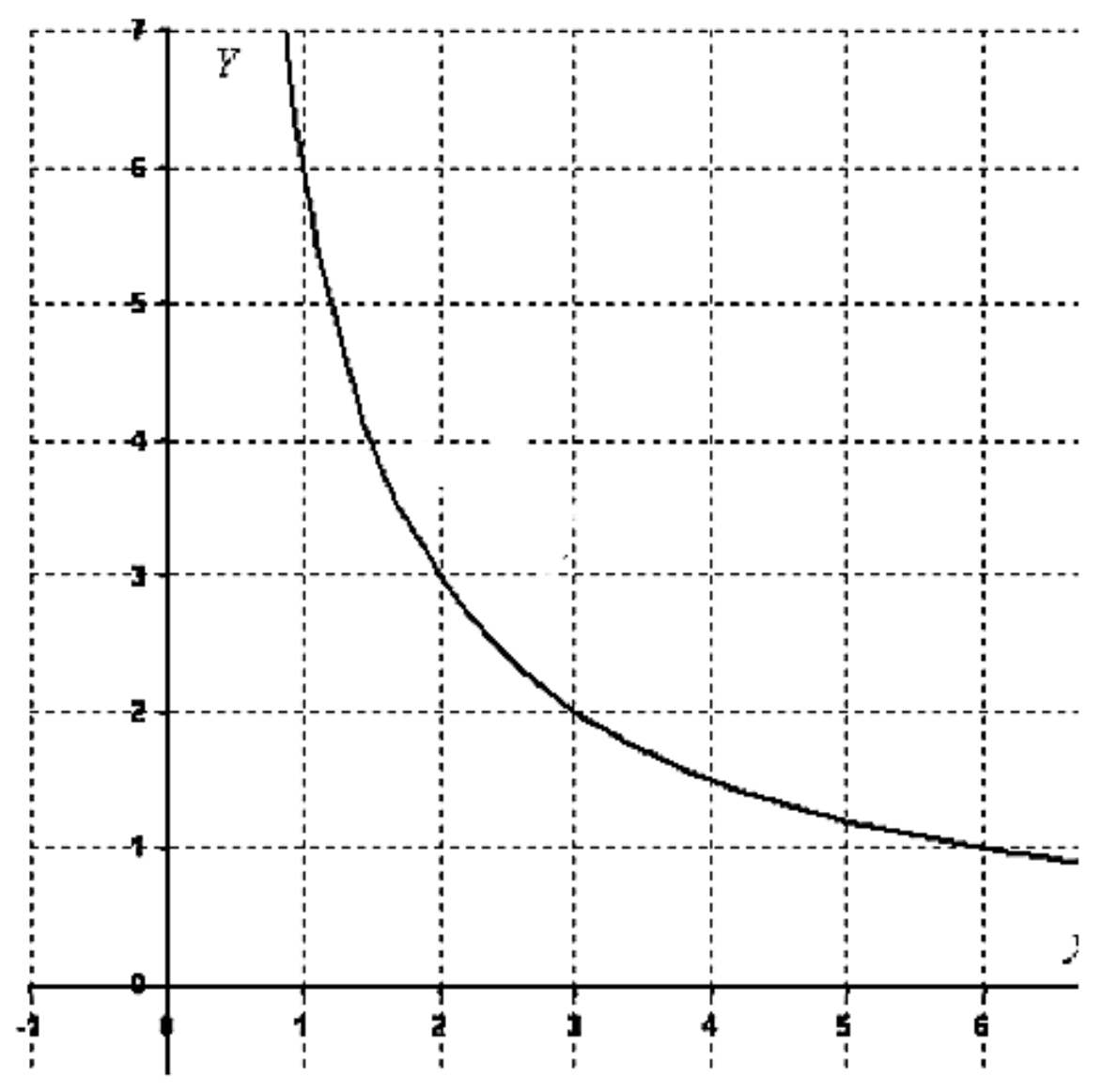

Рис. 1

Множественность факторов, оказывающих влияние на эффективность функционирования НК обусловлена исключительным местом и положением 
комплекса в структуре всего народного хозяйства, а также динамичностью изменения сред функционирования и осуществлением хозяйственной деятельности в рыночных условиях.

\section{Список литературы}

1. [Электронный pecypc]. - Режим доступа: http://elibrary.ru/item.asp?id= 11716754

2. Хисамутдинов И.А. Основы экономики и теории рынка. $-2010 .-325$ с.

\section{References}

1. [Electronic resource]. - Access mode: http://elibrary.ru/item.asp?id=11716754

2. Khisamutdinov I.A. Fundamentals of economics and market theory. $-2010-$ $325 \mathrm{p}$.

Сушенцева Олеся Васильевна - студентка ФГБОУ ВО «Пермский национальный исследовательский политехнический университет», Россия, Пермь.

Sushentseva Olesya Vasilyevna - student at the FSBEI of HE "Perm National Research Polytechnic University", Russia, Perm. 